\begin{tabular}{|c|c|}
\hline Title & In Situ X-Ray A bsorption Spectroscopy Study of Sn Underpotential Deposition on Ni from Perchloric A cid \\
\hline Author(s) & Seo, M.; Habazaki, Hiroki; Inaba, M.; Y okomizo, M.; Wakabay ashi, T.; Nakay ama, T. \\
\hline Citation & $\begin{array}{l}\text { Journal of The Electrochemical Society, 161(4), H195-H } 202 \\
\text { https://doi.org/10.1149/2.044404jes }\end{array}$ \\
\hline Issue Date & $2014-02-07$ \\
\hline Doc URL & http:/hdl.handle.net/2115/56549 \\
\hline Rights & $\begin{array}{l}\text { () The Electrochemical Society, Inc. 2014. All rights reserved. Except as provided under U.S. copyright law, this work } \\
\text { may not be reproduced, resold, distributed, or modified without the express permission of The Electrochemical Society } \\
\text { (ECS). The archival version of this work was published in Journal of the electrochemical society. }\end{array}$ \\
\hline Type & article \\
\hline File Information & JES161-4 H195-H202.pdf \\
\hline
\end{tabular}

Instructions for use 


\title{
In Situ X-Ray Absorption Spectroscopy Study of Sn Underpotential Deposition on Ni from Perchloric Acid
}

\author{
M. Seo, ${ }^{\mathrm{a}, *, \mathrm{z}}$ H. Habazaki, ${ }^{\mathrm{a}, * *}$ M. Inaba, ${ }^{\mathrm{b}}$ M. Yokomizo, ${ }^{\mathrm{b}}$ T. Wakabayashi, ${ }^{\mathrm{b}}$ and T. Nakayama ${ }^{\mathrm{c}}$ \\ ${ }^{a}$ Division of Materials Chemistry, Faculty of Engineering, Hokkaido University, Sapporo, Hokkaido 060-8628, Japan \\ ${ }^{b}$ Kobelco Research Institute, Inc., Kobe, Hyogo 651-2271, Japan \\ ${ }^{c}$ Materials Research Laboratory, Kobe Steel Ltd., Kobe, Hyogo 651-2271, Japan
}

\begin{abstract}
In situ X-ray absorption spectroscopy (XAS) was applied to investigate the Sn underpotential deposition (UPD) on Ni surface from $0.2 \mathrm{M} \mathrm{HClO}_{4}$ solution containing $10^{-3} \mathrm{M} \mathrm{Sn}^{2+}$ with relation to the inhibition effect of Sn on aqueous corrosion of Ni. The periodical emersion method under potentiostatic polarization, using the surface-roughened Ni plate (surface roughness $S_{\mathrm{r}}=78.3$ ) as a working electrode was employed to detect sensitively the sub-monolayer coverage of Sn on Ni. The Sn K-edge absorption spectra in a scanning XAS mode were measured by monitoring the $\mathrm{Sn} \mathrm{K}_{\alpha 1}$ fluorescence line. The Sn K-edge absorption near-edge structure (XANES) in the Sn-UPD potential region has revealed that the Sn-UPD layer on Ni is oxygenated. The extended X-ray absorption fine structure (EXAFS) analysis was performed with a two shell fit of the nearest neighbor Sn-Ni and Sn-O interactions, assuming that the uppermost Ni surface exposed to the solution is mainly oriented to the (111) plane. The results have indicated that Sn atoms are substituted like a surface alloy at face-center-cubic sites in the first Ni layer and further bonded with oxygen atoms. The strong inhibition effect of $\mathrm{Sn}$ on aqueous corrosion of $\mathrm{Ni}$ is ascribed to the bond between $\mathrm{Sn}$ and $\mathrm{O}$ atoms in addition to the bond between $\mathrm{Sn}$ and $\mathrm{Ni}$ atoms.
\end{abstract}

(C) 2014 The Electrochemical Society. [DOI: 10.1149/2.044404jes] All rights reserved.

Manuscript submitted November 11, 2013; revised manuscript received January 30, 2014. Published February 7, 2014.

The formation of metal monolayer on a foreign metal electrode at potentials more noble than the equilibrium potential of bulk electrodeposition is termed underpotential deposition (UPD). The UPD of $\mathrm{Sn}$ on $\mathrm{Pt}^{1-4}$ has been investigated with relation to electrocatalysts for electro-oxidation of $\mathrm{CO},{ }^{5} \mathrm{HCOOH}^{6}$ or methanol ${ }^{7-10}$ while Sn-plating has been widely used in steel industry due to the corrosion prevention of iron and steels by $\mathrm{Sn}^{11-14}$ Our recent study ${ }^{15}$ has revealed that $10^{-3} \mathrm{M} \mathrm{Sn}^{2+}$ added in $0.2 \mathrm{M} \mathrm{HClO}_{4}$ inhibits completely the anodic dissolution of pure $\mathrm{Ni}$, suggesting the participation of Sn-UPD in corrosion inhibition of $\mathrm{Ni}$. We reported previously that the addition of $\mathrm{Pb}^{2+}$ in acidic perchlorate solution suppresses the anodic dissolution of $\mathrm{Ni}$ and the suppression of $\mathrm{Ni}$ corrosion is ascribed to the Pb-UPD. ${ }^{16}$ Moreover, it was confirmed by in situ surface X-ray absorption spectroscopy (XAS) that the $\mathrm{Pb}$ species deposited on $\mathrm{Ni}$ are in metallic state. ${ }^{17}$

The following differences, however, are distinct between inhibition effects of $\mathrm{Pb}^{2+}$ and $\mathrm{Sn}^{2+}$ on anodic dissolution of $\mathrm{Ni}$. In the case of $\mathrm{Pb}^{2+}$, although the $\mathrm{Pb}$ atoms deposited on $\mathrm{Ni}$ in the UPD potential region suppress the anodic dissolution of $\mathrm{Ni}$, the anodic dissolution of $\mathrm{Ni}$ is re-activated due to anodic stripping of the deposited $\mathrm{Pb}$ atoms as the potential shifts to the noble direction and $\mathrm{Ni}$ is subsequently passivated. ${ }^{16}$ In contrast in the case of $\mathrm{Sn}^{2+}$, no anodic dissolution of $\mathrm{Ni}$ is observed in the wide potential region exceeding the Sn-UPD region. ${ }^{15}$ The X-ray photoelectron spectroscopy (XPS) analysis has showed that in the case of $\mathrm{Pb}^{2+}$, any $\mathrm{Pb}$ species are not detected on the passive surface of $\mathrm{Ni},{ }^{16}$ while in the case of $\mathrm{Sn}^{2+}, \mathrm{Sn}$ species are detected on the passive surface. ${ }^{15}$ The difference between the inhibition behavior of $\mathrm{Pb}^{2+}$ and $\mathrm{Sn}^{2+}$ on anodic dissolution of $\mathrm{Ni}$ may result from the difference in chemical stability between $\mathrm{Pb}$ - and Sn-UPD layers on Ni.

In situ surface XAS, using a synchrotron radiation ${ }^{18,19}$ is powerful tool for investigating the chemical state and local atomic structure of the UPD layer on metal electrode in aqueous solution. In general, XAS is not sensitive to a surface since X-rays of high energy have long propagation length in condensed matter. Nevertheless, the information limited to only a surface can be obtained by employing surface XAS with grazing incidence excitation and fluorescence detection. In application of surface XAS to the electrochemical UPD systems, specimen electrode with a smooth surface and a thin electrolyte layer on the surface are indispensable for grazing incidence excitation and for fluorescence detection. This technique has been applied to many

\footnotetext{
*Electrochemical Society Fellow.

**Electrochemical Society Active Member.

${ }^{\mathrm{z}}$ E-mail: masaseo@eng.hokudai.ac.jp
}

UPD layer/noble metal electrode systems such as $\mathrm{Pb}$ on $\mathrm{Ag}(111),{ }^{20}$ $\mathrm{Cu}$ on $\mathrm{Au}(111)^{21}$ or on $\mathrm{Au}(100),{ }^{22,23} \mathrm{Cu}$ on $\mathrm{Pt}(111)^{24}$ or on $\mathrm{Pt}(100)^{25}$ and $\mathrm{Zn}$ on $\mathrm{Au}(111)^{26}$ where aqueous corrosion does not take place, thus, the composition of thin electrolyte layer does not change and the smooth interface keeps during measurement. In the case of $\mathrm{Ni}$ electrode susceptible to aqueous corrosion in acidic solutions, however, the above technique may be unacceptable because of the changes in surface morphology and the precipitation of corrosion products in the thin electrolyte layer. In application of surface XAS to the metal electrode susceptible to corrosion, the use of thick electrolyte layer with sufficient volume/surface ratio is necessary to avoid the compositional change of electrolyte and the precipitation of corrosion products, while the XAS information originated from metal ions (e.g. $\mathrm{Sn}^{2+}$ ) in the solution has to be removed to separate the information from the same metal (e.g. Sn)-UPD layer.

The emersion method developed by Hansen et al. ${ }^{27,28}$ for spectroscopy of the solid electrode/solution interface may be useful to avoid the information from metal ion in solution. Instead of grazing incidence excitation, Stefan and Scherson ${ }^{29}$ developed the rotated emersion method for the study on passivity of $\mathrm{Zn}$ in an alkaline solution and succeeded in monitoring the growth and reduction processes of passive film. The employment of the specimen with large surface roughness is indispensable for surface XAS study without grazing incidence excitation. We have recently developed the periodical emersion method ${ }^{17}$ using the surface-roughened Ni plate for in situ surface XAS study of the Pb-UPD on Ni in acidic perchlorate solution and succeeded in measuring the XAS spectra of Pb-UPD layer on $\mathrm{Ni}$.

In this study, the XAS spectra of Sn species deposited on Ni from perchloric acid containing $\mathrm{Sn}^{2+}$ were measured by employing the periodical emersion method ${ }^{17}$ to investigate the chemical state and local structure of Sn-UPD layer that would provide new knowledge to understand the inhibition effect of $\mathrm{Sn}^{2+}$ on aqueous corrosion of $\mathrm{Ni}$.

\section{Experimental}

Specimen preparation.- Polycrystalline Ni plate with a size of $20 \times 25 \times 0.5 \mathrm{~mm}$ (purity $>99.6 \%$, Nilaco Co.) was used as a specimen substrate and was mechanically polished on SiC papers. The preparation of the surface-roughened Ni specimen was achieved by two-step electrodeposition of $\mathrm{Ni}$ on the $\mathrm{Ni}$ substrate at $60^{\circ} \mathrm{C}$ and $25^{\circ} \mathrm{C}$ in a mixed solution of $\mathrm{NiSO}_{4} / \mathrm{NiCl}_{2}$ and subsequently etching in $10 \%$ nitric acid. The surface-roughened $\mathrm{Ni}$ plate is named the sr-Ni plate for abbreviation in this paper. The surface roughness (the ratio of real surface area to geometrical surface area), $S_{\mathrm{r}}=78.3$ of the sr-Ni plate was determined by the BET method (BEL JAPAN, INC., 
BELSORP-max-12 N-VP). Details (surface morphology, thickness, average crystal size, etc.) of the sr-Ni layer are given in our previous paper. $^{17}$ The electrolyte solution used for experiments was $0.2 \mathrm{M}$ $\mathrm{HClO}_{4}$ solution containing $10^{-3} \mathrm{M} \mathrm{Sn}^{2+}$. Tin was added as $\mathrm{SnO}$ to give $10^{-3} \mathrm{M} \mathrm{Sn}^{2+}$ in solution. The electrolyte solution was prepared from guaranteed grade $60 \% \mathrm{HClO}_{4}$ (Kanto Chemical Co. Inc.) and high purity $(99.5 \%>$ ) SnO (Koujundo Chemical Lab. Co. Ltd.) with ultrapure water supplied through a super Milli Q filter system. During preparation of the solution containing $10^{-3} \mathrm{M} \mathrm{Sn}^{2+}$, the possibility for an oxidation of $\mathrm{Sn}^{2+}$ to $\mathrm{Sn}^{4+}$ by air dissolved in solution is not excluded. The $\mathrm{Sn}^{4+}$ species in solution, however, should be minor since the solution is deaerated in a reservoir immediately after the preparation.

In situ XAS measurement.- The XAS measurements were performed on BL16B2 beam line at the Super Photon Ring- $8 \mathrm{GeV}$ (Spring-8), Hyogo, Japan. The electrochemical cell was so mounted on a stage as to locate the Kapton window side at an angle of $45^{\circ}$ relative to the incident X-ray beam. The sr-Ni plate was set into the cell in parallel to the Kapton window. The distance between sr-Ni plate and Kapton window was kept about $1 \mathrm{~mm}$. After air in the cell was completely removed by flowing ultra-pure argon gas in the cell, the electrolyte solution was supplied from the solution reservoir up to the level-H in the cell at which the sr-Ni plate was fully immersed in solution. The potential of the sr-Ni plate was measured with a Ag/ $\mathrm{AgCl} /$ sat. $\mathrm{KCl}$ reference electrode through a Luggin capillary tube and referred to the standard hydrogen electrode (SHE). The Pt plate was used as a counter electrode.

At first, the sr-Ni plate was potentiostatically polarized in solution until the polarization current attained steady state. It took about $30 \mathrm{~min}$ to attain almost the steady state. Afterwards, the periodical emersion of the sr-Ni plate under potentiostatic polarization was made as follows: 1) the solution in the cell was lowered to the level-L at which the upper part of the sr-Ni plate was emerged and the X-ray beam was irradiated to the part of the sr-Ni plate emerged from the level-L for data collection by a scanning XAS mode, 2) after the data collection for $2 \mathrm{~min}$, the solution was raised to the level-H and the sr-Ni plate was fully immersed in solution for $2 \mathrm{~min}$, and 3) the solution was lowered again to the level-L for data collection and the above procedure was repeated at least ten cycles. The level-H was higher by $10 \mathrm{~mm}$ than the level-L. The volumes of the solution in the cell at levels-H and $-\mathrm{L}$ were 273 and $228 \mathrm{~cm}^{3}$, respectively. The X-ray beam was irradiated to the rectangular area $(2 \mathrm{~mm} \times 7 \mathrm{~mm})$ of the sr-Ni plate located at the middle of the levels- $\mathrm{H}$ and $-\mathrm{L}$, i.e., above $5.0 \mathrm{~mm}$ from the level-L. Details of the electrochemical cell and solution level-control system for periodical emersion method were described elsewhere. ${ }^{17}$

The Sn K-edge absorption spectra were measured by monitoring the $\mathrm{Sn} \mathrm{K} \mathrm{K}_{\alpha 1}$ fluorescence line at $25.27 \mathrm{keV}$ obtained from a 19-element Germanium Array Detector (Canberra, Inc.). The incident X-ray beam was collimated with slits to the rectangle of $5 \mathrm{~mm}$ in length $\times 2 \mathrm{~mm}$ in width. The Si (311) double-crystal monochrometer was used and the photon energy was calibrated relative to the sharp pre-edge peak $(8.9803 \mathrm{keV})$ of metallic $\mathrm{Cu}$. The photon energy was scanned from $28.90 \mathrm{keV}$ to $30.70 \mathrm{keV}$ for 2 min to collect the fluorescence data. Afterwards, the photon energy was scanned back to $28.90 \mathrm{keV}$ for 1 min. The scanning time of the photon energy was synchronized with the periodical emersion through the combination of DAQ (NI PCIMIO-16XE-50) for the XAS measurement and LabVIEW software for the solution-control system. Moreover, the Sn K-edge absorption spectra of metallic $\beta$-Sn foil, $\mathrm{SnO}$ (romarchite) and $\mathrm{SnO}_{2}$ (cassiterite) as standard materials were measured in the same photon energy range for comparison.

\section{Results and Discussion}

Polarization behavior of the sr-Ni plate. - Figure 1 shows the cyclic voltammogram $(\mathrm{CV})$ of the smooth Ni plate prior to the surface roughening-treatment measured at a potential sweep rate of $10 \mathrm{mV} \mathrm{s}^{-1}$ in the potential range between $-0.20 \mathrm{~V}$ and $0.40 \mathrm{~V}$ in deaerated 0.2

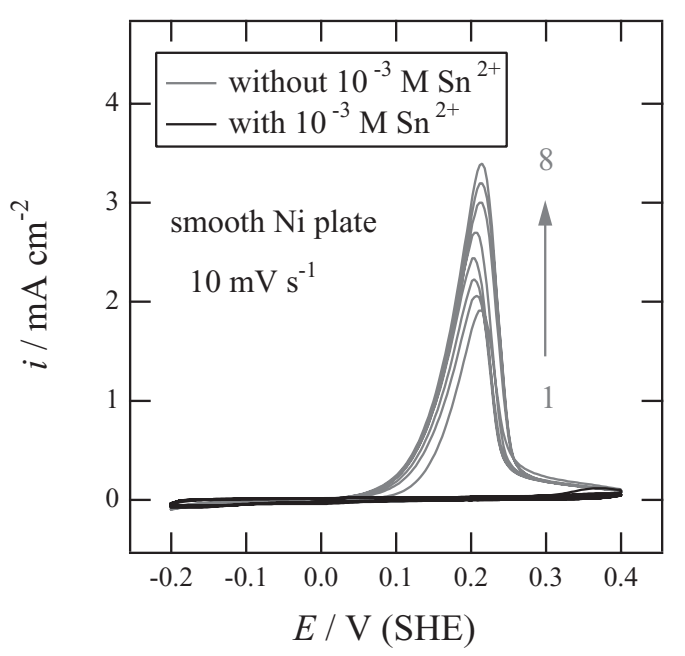

Figure 1. Cyclic voltammogram $(\mathrm{CV})$ of the smooth $\mathrm{Ni}$ plate prior to the surface roughening-treatment measured at a potential sweep rate of $10 \mathrm{mV} \mathrm{s}^{-1}$ in the potential range between $-0.20 \mathrm{~V}$ and $0.40 \mathrm{~V}$ in deaerated $0.2 \mathrm{M} \mathrm{HClO}_{4}$ solution containing $10^{-3} \mathrm{M} \mathrm{Sn}^{2+}$. The $\mathrm{CV}$ in the solution without $10^{-3} \mathrm{M}$ $\mathrm{Sn}^{2+}$ is also shown in Fig. 1 for comparison. Numerical numbers in Fig. 1 represent the cycle numbers.

$\mathrm{M} \mathrm{HClO}_{4}$ solution containing $10^{-3} \mathrm{M} \mathrm{Sn}^{2+}$. The $\mathrm{CV}$ in the solution without $10^{-3} \mathrm{M} \mathrm{Sn}^{2+}$ is also shown in Fig. 1 for comparison. The anodic dissolution current of the smooth $\mathrm{Ni}$ plate in the solution without $10^{-3} \mathrm{M} \mathrm{Sn}^{2+}$ rises rapidly at about $0.05 \mathrm{~V}$ and the anodic current peaks observed at about $0.2 \mathrm{~V}$ increases with increasing cycle number. In contrast, no anodic current peaks of the smooth Ni plate are observed in the solution with $10^{-3} \mathrm{M} \mathrm{Sn}^{2+}$, indicating that the addition of $10^{-3} \mathrm{M} \mathrm{Sn}^{2+}$ suppresses completely the anodic dissolution. Figure 2 shows the $\mathrm{CV}$ of the sr-Ni plate measured at a potential sweep rate of $1 \mathrm{mV} \mathrm{s}^{-1}$ in the potential range between $-0.22 \mathrm{~V}$ and $0.05 \mathrm{~V}$ in deaerated $0.2 \mathrm{M} \mathrm{HClO}_{4}$ solution containing $10^{-3} \mathrm{M}$ $\mathrm{Sn}^{2+}$. The $\mathrm{CV}$ in the solution without $10^{-3} \mathrm{M} \mathrm{Sn}^{2+}$ is also shown in Fig. 2 for comparison. The current density, $i$, in the ordinate of Fig. 2 was obtained with dividing the current by the real surface

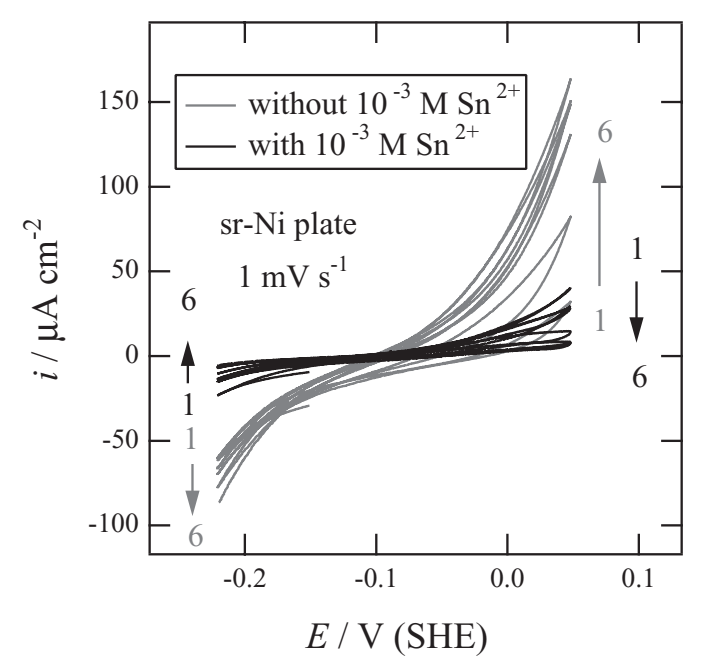

Figure 2. CV of the surface roughened- (sr-)Ni plate measured at a potential sweep rate of $1 \mathrm{mV} \mathrm{s}^{-1}$ in the potential range between $-0.22 \mathrm{~V}$ and $0.05 \mathrm{~V}$ in deaerated $0.2 \mathrm{M} \mathrm{HClO}_{4}$ solution containing $10^{-3} \mathrm{M} \mathrm{Sn}^{2+}$. The $\mathrm{CV}$ in the solution without $10^{-3} \mathrm{M} \mathrm{Sn}^{2+}$ is also shown in Fig. 2 for comparison. Numerical numbers in Fig. 2 represent the cycle numbers. The current density, $i$, in the ordinate of Fig. 2 was obtained with dividing the current by the real surface area of the sr-Ni plate. 


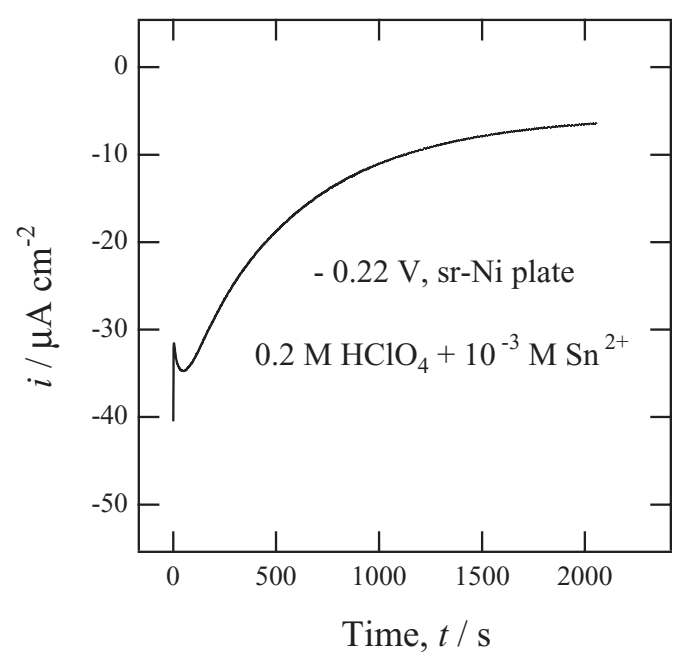

Figure 3. Time-variation of current density during potentiostatic polarization of the sr-Ni plate at $-0.22 \mathrm{~V}$ in the solution with $10^{-3} \mathrm{M} \mathrm{Sn}^{2+}$. The current density, $i$, in the ordinate of Fig. 3 was obtained with dividing the current by the real surface area of the sr-Ni plate.

area of the sr-Ni plate. The cathodic limit of $-0.22 \mathrm{~V}$ in Fig. 2 corresponds to the equilibrium potential ${ }^{30}$ of Sn-electrodeposition in $10^{-3} \mathrm{M} \mathrm{Sn}^{2+}$ solution. It is clear from Fig. 2 that the addition of $10^{-3} \mathrm{M} \mathrm{Sn}^{2+}$ suppresses not only anodic dissolution of Ni but also hydrogen evolution. The polarization currents of the sr-Ni plate in the solution without $10^{-3} \mathrm{M} \mathrm{Sn}^{2+}$ increase with increasing cycle number, which may come from gradual removal of air-formed film on the sr-Ni plate during cycling.

According to Kolb et al., ${ }^{31,32}$ the potential width of UPD, $\Delta E_{\mathrm{UPD}}$, can be approximately estimated from the following empirical relation.

$$
\Delta E_{\mathrm{UPD}} \approx 0.5\left(\phi_{\mathrm{S}}-\phi_{\mathrm{M}}\right) / e
$$

where $\phi_{\mathrm{S}}$ and $\phi_{\mathrm{M}}$ are the work functions of foreign substrate metal and UPD metal, respectively, and $e$ is the elementary charge. If taking $\phi_{\mathrm{S}}=5.15 \mathrm{eV}$ for polycrystalline $\mathrm{Ni}^{33}$ and $\phi_{\mathrm{M}}=4.42 \mathrm{eV}$ for polycrystalline $\mathrm{Sn},{ }^{33} \Delta E_{\mathrm{UPD}}=0.37 \mathrm{~V}$ is obtained from Eq. 1 . The $\mathrm{Sn}$ UPD potential region estimated for the system of $\left(10^{-3} \mathrm{M} \mathrm{Sn}^{2+} / \mathrm{Ni}\right)$, therefore, is from $-0.22 \mathrm{~V}$ to $0.15 \mathrm{~V}$. The anodic potential limit $(0.05 \mathrm{~V})$ of the $\mathrm{CV}$ in Fig. 2 is still in the Sn-UPD potential region. Figure 3 shows the time-variation of current density during potentiostatic polarization of the sr-Ni plate at $-0.22 \mathrm{~V}$ in the solution with $10^{-3} \mathrm{M} \mathrm{Sn}^{2+}$. The cathodic current peak emerged at the initial stage may be associated with the Sn-electrodeposition (i.e., UPD of Sn) on the sr-Ni plate. The cathodic current density almost keeps constant with time after $30 \mathrm{~min}$. The cathodic current density (about $7 \mu \mathrm{A} \mathrm{cm}^{-2}$ ) after $30 \mathrm{~min}$ is mainly due to hydrogen evolution. The hydrogen bubbles on the sr-Ni plate, however, could not be observed with a naked eye. Figure 4 shows the typical example of changes in current density of the sr-Ni plate at $0.05 \mathrm{~V}$ in the solution with $10^{-3}$ $\mathrm{M} \mathrm{Sn}^{2+}$ during periodical emersion-XAS measurements. The anodic current changes periodically at $0.05 \mathrm{~V}$ synchronized with the periodical changes between solution levels- $\mathrm{H}$ and $-\mathrm{L}$ in the electrochemical cell. The high and low anodic current plateaus in Fig. 4 correspond to the solution levels- $\mathrm{H}$ and $-\mathrm{L}$, respectively. The ratio of low to high current plateau is almost consistent with the surface area ratio (0.6) of the sr-Ni plate immersed in solution. The instantaneous and small overshoots of current density are observed during every transition from the solution level-H to $-\mathrm{L}$, which may be caused by electric noises from the solution level control system.

Sn K-edge XAS spectra.- The Sn K-edge XAS spectra were measured for the sr-Ni plate kept at five different potentials of $-0.22 \mathrm{~V}$, $-0.15 \mathrm{~V},-0.05 \mathrm{~V}, 0.0 \mathrm{~V}$ and $0.05 \mathrm{~V}$ in the solution. The XAS measurement was initiated at $-0.22 \mathrm{~V}$ and directed in turn to the more

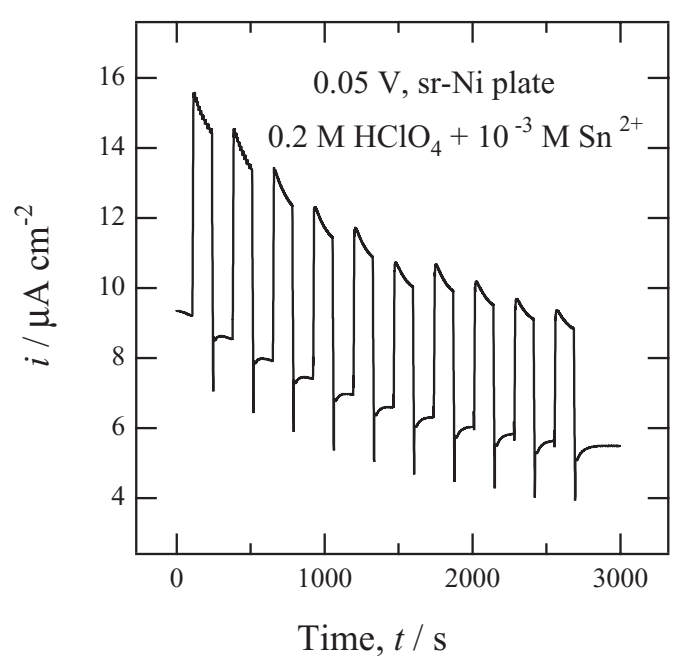

Figure 4. Typical example of changes in current density of the sr-Ni plate at $0.05 \mathrm{~V}$ in the solution with $10^{-3} \mathrm{M} \mathrm{Sn}^{2+}$ during periodical emersion-XAS measurements. The current density, $i$, in the ordinate of Fig. 4 was obtained with dividing the current by the real surface area of the sr-Ni plate fully immersed in solution. The high and low anodic current plateaus in Fig. 4 correspond to the solution levels- $\mathrm{H}$ and $-\mathrm{L}$, respectively.

noble potential. The reason why the XAS measurement was initiated at $-0.22 \mathrm{~V}$ is that an air-formed film on $\mathrm{Ni}$ can be easily reduced at the less noble potential ${ }^{34}$ and the influence of air-formed film on the XAS measurement is minimized. Figure 5 shows the raw Sn Kedge XAS spectra that were collected by ten times-energy scanning and averaged for the sr-Ni plate kept at $-0.15 \mathrm{~V}$ and $0.05 \mathrm{~V}$. The Sn $\mathrm{K}_{\alpha 1}$ fluorescence intensity divided by the incident X-ray intensity was taken as absorbance, $\mu t$, in the ordinate of Fig. 5. The sharp rise of the spectrum in Fig. 5 corresponds to the Sn K-edge. Unfortunately, it is found that some $\mathrm{Sn}$ species from the solution are adhered to the inside wall of the Kapton window, which induces the difficult problem for in-situ XAS analysis of Sn-UPD layer on Ni. The Sn K-edge XAS spectrum of the Sn species on the Kapton window is measured under the same experimental conditions after removal of the sr-Ni plate and

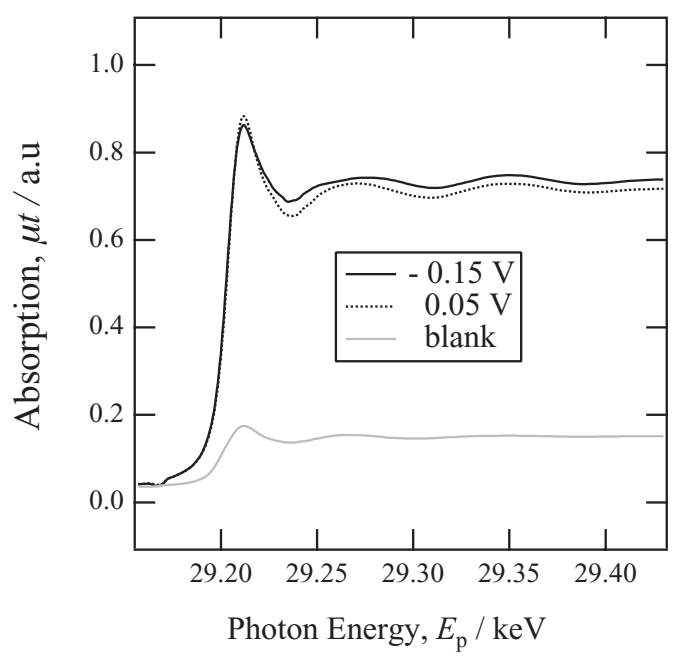

Figure 5. Raw Sn K-edge XAS spectra that were collected by ten timesenergy scanning and averaged for the sr-Ni plate kept at $-0.15 \mathrm{~V}$ and $0.05 \mathrm{~V}$. The $\mathrm{Sn} \mathrm{K}_{\alpha 1}$ fluorescence intensity divided by the incident X-ray intensity was taken as absorbance, $\mu t$, in the ordinate of Fig. 5. The blank spectrum in Fig. 5 represents the Sn K-edge XAS spectrum of the Sn species on the Kapton window measured under the same experimental condition after removal of the sr-Ni plate. 


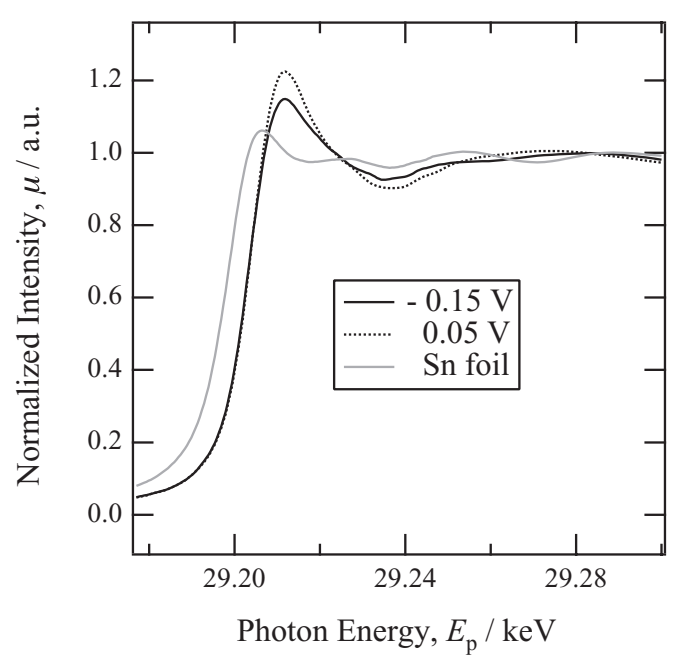

Figure 6. X-ray absorption near-edge structure (XANES) spectra of Sn Kedge at $-0.15 \mathrm{~V}$ and $0.05 \mathrm{~V}$ for the sr-Ni plate normalized after the subtraction of the blank spectrum. The normalized Sn K-edge XANES spectrum of metallic $\beta$-Sn foil is also shown in Fig. 6 for comparison.

is represented by "blank" in Fig. 5. The intensity of the blank spectrum is about $20 \%$ of that of the spectrum measured at $-0.15 \mathrm{~V}$ or $0.05 \mathrm{~V}$ for the sr-Ni plate as shown in Fig. 5. Nevertheless, it is feasible to get the real spectra of Sn-UPD layer on the sr-Ni plate by subtracting the blank spectrum from the spectra measured for the sr-Ni plate since the blank spectrum intensity attained already to the steady state and did not change for every experiment.

Figure 6 shows the X-ray absorption near-edge structure (XANES) spectra of Sn K-edge at $-0.15 \mathrm{~V}$ and $0.05 \mathrm{~V}$ for the sr-Ni plate normalized after the subtraction of the blank spectrum. The normalized Sn K-edge XANES spectrum of metallic $\beta$-Sn foil is also shown in Fig. 6 for comparison. The normalized Sn K-edge XANES spectrum at $-0.15 \mathrm{~V}$ or $0.05 \mathrm{~V}$ for the sr-Ni plate shifts to the high photonenergy side by about $5 \mathrm{eV}$ as compared with that of metallic $\beta$-Sn foil and is close to that of standard $\mathrm{SnO}_{2}$ (not shown in Fig. 6 because of the overlapped spectra), indicating that the Sn species on the sr-Ni plate are in oxidative state rather than metallic state. Moreover, the difference between normalized Sn K-edge spectra at $-0.15 \mathrm{~V}$ and $0.05 \mathrm{~V}$ for the sr-Ni plate suggests the potential dependence of $\mathrm{Sn}$ species on $\mathrm{Ni}$, details of which are discussed later from the extended $\mathrm{X}$-ray absorption fine structure (EXAFS) analysis. The trace amount of solution may remain on the sr-Ni plate due to capillary action for the rough surface during emersion to give the contribution of $\mathrm{Sn}^{2+}$ ions to the Sn K-edge XAS spectra. The average thickness of the solution remained on the sr-Ni plate was estimated to be about $20 \mu \mathrm{m}$ from the gravimetrical measurement. ${ }^{17}$ The amount of $\mathrm{Sn}^{2+}$ ions in the solution with a thickness of $20 \mu \mathrm{m}$ is $1.2 \times 10^{15}$ ions $\mathrm{cm}^{-2}$. The amount of $\mathrm{Sn}$ species adsorbed on $\mathrm{Ni}$ in the UPD potential range more noble than the equilibrium potential for electrodeposition of Sn would not exceed the Sn-monolayer as generally accepted for many UPD systems. ${ }^{32,35}$ The amount of $\mathrm{Sn}$ atoms corresponding to the monolayer on smooth $\mathrm{Ni}$ (111) surface is calculated to be $1.73 \times 10^{15}$ atoms $\mathrm{cm}^{-2}$ by taking into account the difference in atomic radius between $\operatorname{Sn}\left(r_{\mathrm{Sn}}=1.40 \AA\right.$ for $\alpha-\mathrm{Sn})$ and $\mathrm{Ni}\left(r_{\mathrm{Ni}}=1.25 \AA\right)$. Therefore, the amount of Sn atoms corresponding to the monolayer on the sr-Ni plate surface is estimated to be $1.36 \times 10^{17}$ atoms cm $\mathrm{cm}^{-2}$ by multiplying $1.73 \times 10^{15}$ atoms cm $\mathrm{cm}^{-2}$ by the surface roughness $\left(S_{\mathrm{r}}=78.3\right)$. The comparison between the amount of $\mathrm{Sn}$ atoms corresponding to the monolayer on the sr-Ni plate surface and the amount $\left(1.2 \times 10^{15}\right.$ ions $\left.\mathrm{cm}^{-2}\right)$ of $\mathrm{Sn}^{2+}$ ions contained in the remained solution layer suggests that the contribution of $\mathrm{Sn}^{2+}$ to the Sn K-edge XAS spectra is negligibly small (less than $1 \%$ ).

EXAFS analysis.- The local atomic structure of the Sn-UPD layer on $\mathrm{Ni}$ and its potential dependence can be evaluated from the EXAFS

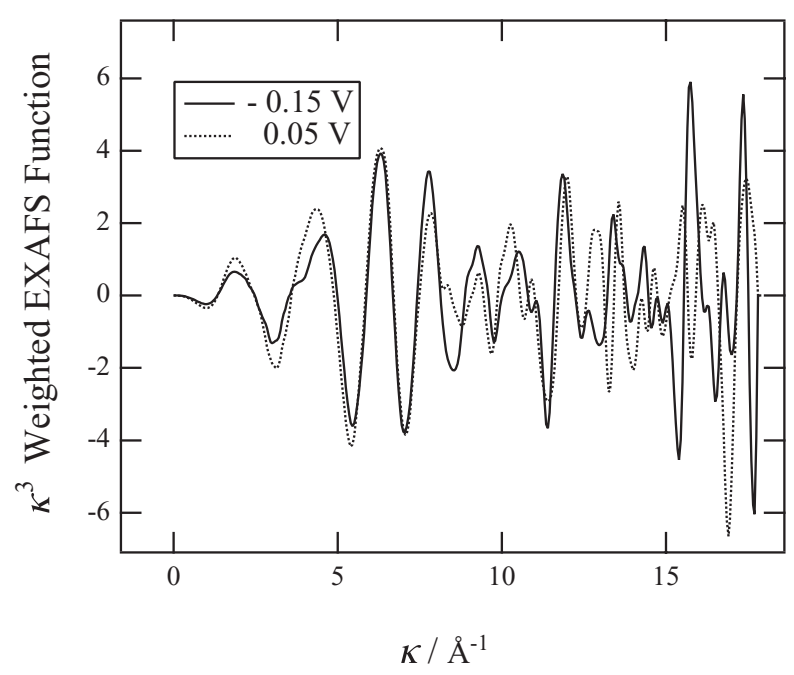

Figure 7. $\kappa^{3}$-weighted EXAFS functions ( $\kappa^{3} \chi$ vs. $\kappa$ curves) obtained the $S n$ K-edge XAS spectra at $-0.15 \mathrm{~V}$ and $0.05 \mathrm{~V}$ for the sr-Ni plate.

analysis. The oscillatory part, $\chi(\kappa)$ of the Sn K-edge XAS spectrum above the absorption edge for the sr-Ni plate was extracted as a function of wave number, $\kappa$, by removing the smooth background. Figure 7 shows the $\kappa^{3}$-weighted EXAFS functions ( $\kappa^{3} \chi$ vs. $\kappa$ curves) obtained the Sn K-edge XAS spectra at $-0.15 \mathrm{~V}$ and $0.05 \mathrm{~V}$ for the sr-Ni plate. The EXAFS features are discernible from the Fig. 7 although the data are noisy in the $\kappa$ range higher than $12.5 \AA^{-1}$. The subtraction of the blank spectrum from the raw XAS spectra (Fig. 5) may provide the noisy EXAFS data in the high $\kappa$-range. The window of $\kappa=2.5 \AA^{-1}$ to $12.5 \AA^{-1}$, therefore, was set for Fourier transforming the EXAFS data. Figure 8 shows the radial structure functions $(|\chi(R)|$ vs. $R$ curves) obtained by Fourier transforming the EXAFS data for the sr-Ni plate kept at various potentials. The radial structure functions in Fig. 8 have two major peaks, $\mathrm{P}_{\mathrm{A}}$ at $R=1.7 \AA$ and $\mathrm{P}_{\mathrm{B}}$ at $\mathrm{R}=2.2 \AA$, the heights of which depend on the potential. The peak height at $R=1.7 \AA$ increases as the potential shifts to the noble direction, while the peak height at $R=2.2 \AA$ decreases reversely. These two peaks correspond to the first few coordination shells in the vicinity of absorbing Sn atoms. Moreover, the small broad peaks or multiple peaks are observed in the range of $R=3 \sim 4 \AA$. These small peaks, however, have no systematic potential dependences although the broad peak at $0.05 \mathrm{~V}$ is relatively high.

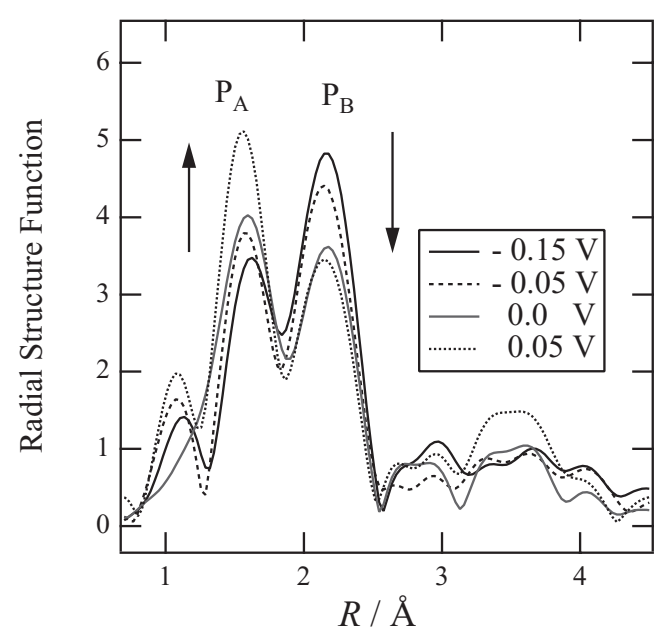

Figure 8. Radial structure functions $(|\chi(R)|$ vs. $R$ curves) obtained by Fourier transforming the EXAFS data in the range of $\kappa=2.5 \AA^{-1}$ to $12.5 \AA^{-1}$ for the sr-Ni plate kept at various potentials. 


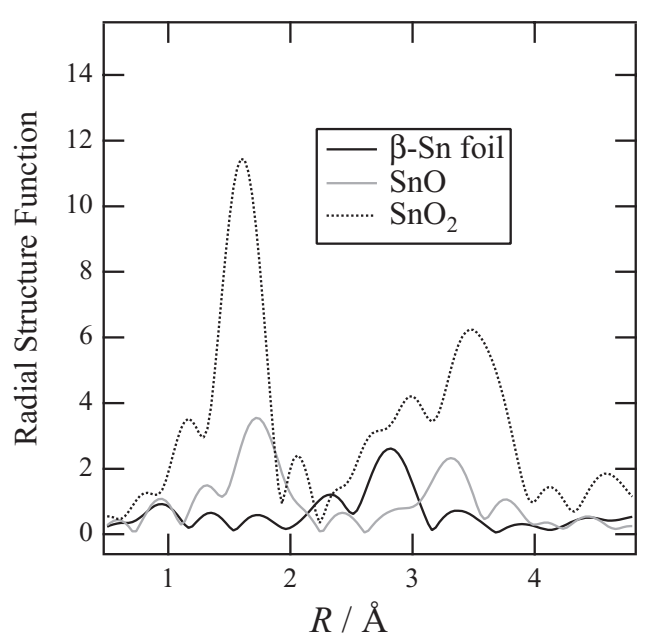

Figure 9. Radial structure functions of $\mathrm{Sn}$ standard materials $\left(\beta-\mathrm{Sn}\right.$ foil, $\mathrm{SnO}_{2}$ and $\mathrm{SnO}$ ) obtained under the same condition of Sn K-edge XAS measurement.

The radial structure functions of Sn standard materials ( $\beta$-Sn foil, $\mathrm{SnO}_{2}$ and $\mathrm{SnO}$ ) obtained under the same conditions of Sn K-edge XAS measurement are shown in Fig. 9 for comparison. The radial structure function of $\mathrm{SnO}_{2}$ in Fig. 9 has one major peak at $R=1.7 \AA$ and multiple peaks in the range of $R=2.5 \sim 4 \AA$, which is consistent with the literature. ${ }^{36}$ The major peak at $R=1.7 \AA$ in the radial structure function of $\mathrm{SnO}_{2}$ corresponds to the nearest neighbor (inter-atomic) Sn-O distance in $\mathrm{SnO}_{2}$ and the multiple peaks in the range of $R=2.5$ $\sim 4 \AA$ are associated with the nearest or second near neighbor $\mathrm{Sn}-$ $\mathrm{Sn}$ distance in addition to the second near neighbor $\mathrm{Sn}-\mathrm{O}$ distance. The major peaks at $R=1.85 \AA$ and $3.3 \AA$ in the radial structure function of $\mathrm{SnO}$ correspond to the nearest neighbor $\mathrm{Sn}-\mathrm{O}$ and $\mathrm{Sn}-\mathrm{Sn}$ distances in $\mathrm{SnO}$, respectively. According to the crystallography ${ }^{37}$ of Sn oxides, the nearest neighbor Sn-O distance $\left(d_{\mathrm{Sn}-\mathrm{O}}=2.05 \AA\right)$ for $\mathrm{SnO}_{2}$ is shorter than that $\left(d_{\mathrm{Sn}-\mathrm{O}}=2.22 \AA\right)$ for $\mathrm{SnO}$. The difference in radial structure function between $\mathrm{SnO}_{2}$ and $\mathrm{SnO}$ is consistent with the crystallographic data ${ }^{37}$ of $\mathrm{Sn}$ oxides. The major peak at $R=2.8 \AA$ in the radial structure functions of $\beta$-Sn corresponds to the nearest neighbor $\mathrm{Sn}-\mathrm{Sn}$ distance, which is also consistent with the literature. ${ }^{36}$ The position $(R=1.7 \AA)$ of the major peak, $\mathrm{P}_{\mathrm{A}}$, in the radial structure functions of the sr-Ni plate (Fig. 8) is close to that of the major peak in the radial structure functions of $\mathrm{SnO}_{2}$ or $\mathrm{SnO}$ (Fig. 9), indicating that the peak, $\mathrm{P}_{\mathrm{A}}$, in Fig. 8 is associated with the $\mathrm{Sn}-\mathrm{O}$ interaction. The position $(R=2.2 \AA)$ of the major peak, $\mathrm{P}_{\mathrm{B}}$, in Fig. 8, however, does not coincide with those of any major peaks for the radial structure functions of $\mathrm{Sn}$ standard materials as shown in Fig. 9. This means that the peak, $\mathrm{P}_{\mathrm{B}}$, is associated with the $\mathrm{Sn}-\mathrm{Ni}$ interaction. The shapes and features of the small broad peaks or multiple peaks at $R=3 \sim 4 \AA$ in Fig. 8 are not strictly the same as those at $R=3 \sim 4 \AA$ for $\mathrm{SnO}_{2}$ in Fig. 9.

The radial structure functions of Sn species adhered to the Kapton window and of Sn colloid ${ }^{15}$ prepared from acidic perchlorate solution containing $10^{-3} \mathrm{M} \mathrm{Sn}^{2+}$ are also shown in Fig. 10 to compare with that of $\mathrm{SnO}_{2}$. Although the radial structure functions of three samples in Fig. 10 are similar each other, the amplitude (particularly in the range of $R>2.5 \AA$ ) at the ordinate of radial structure function for the $\mathrm{Sn}$ species adhered to the Kapton window is significantly attenuated as compared with that for $\mathrm{SnO}_{2}$ or $\mathrm{Sn}$ colloid. It appears that the Sn species adhered to the Kapton window have highly disordered structures $^{38,39}$ like amorphous Sn hydrous oxides or hydroxides.

EXAFS parameters of the Sn-UPD layer on Ni.- All peaks in radial structure function are usually shifted to lower distances compared to the real inter-atomic distance due to the phase shift associated with interaction of the photoelectron wave with the potential of the absorb-

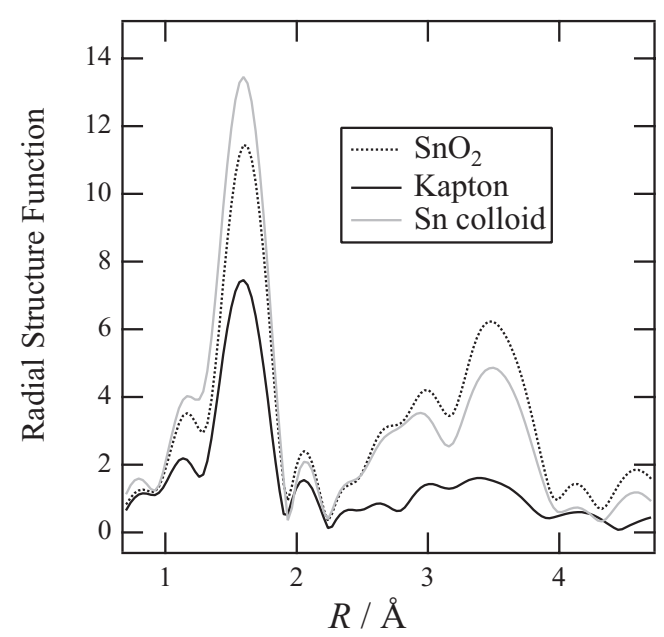

Figure 10. Radial structure functions of Sn species adhered to the Kapton window and of $\mathrm{Sn}$ colloid ${ }^{15}$ prepared from acidic perchlorate solution containing $10^{-3} \mathrm{M} \mathrm{Sn}^{2+}$ for comparison with that of $\mathrm{SnO}_{2}$.

ing and the backscattering atoms. In this study, the determination of the EXAFS parameters (inter-atomic distance, $d$, coordination number, $N$, and Debye-Waller factor, $\sigma^{2}$, energy shift, $\Delta E_{\mathrm{o}}$ and R-factor, $R_{\mathrm{f}}$ ) are limited to the two shells of $\mathrm{Sn}-\mathrm{O}$ and $\mathrm{Sn}-\mathrm{Ni}$ corresponding to the major peaks, $\mathrm{P}_{\mathrm{A}}$ and $\mathrm{P}_{\mathrm{B}}$ in radial structure functions of Fig. 8 since the small broad or multiple peaks in the range of $R>2.5 \AA$ are noisy and have no systematic potential dependences. It is assumed as the first step that the uppermost surface of the sr-Ni plate exposed to solution is mainly oriented to the (111) plane as well as in our previous study of Pb-UPD on Ni. ${ }^{17}$ For the determination of the EXAFS parameters, surface structure model suitable for the Sn-UPD layer on $\mathrm{Ni}$ (111) is proposed at first, the radial structure function based on the proposed model is simulated and the curve fitting is eventually performed between simulation and experiment for the two shells of Sn-O and $\mathrm{Sn}-\mathrm{Ni}$, using the program FEFF 8.2. ${ }^{40,41}$ As a result, the best fit is for the $\mathrm{Sn}$-incorporation model in which $\mathrm{Sn}$ atoms are substituted like a surface alloy at face-center-cubic (fcc) sites in the first Ni layer (see Fig. 11a) and further bonded with oxygen atoms. The curve fitting was also performed for the Sn-overlayer model in which Sn atoms are situated on the three-fold hollow sites of the nearest neighbor $\mathrm{Ni}$ atoms in the first Ni layer (see Fig. 11b) and further bonded with oxygen atoms. The Sn-overlayer model, however, could not bring a good fit. Figures 12 and 13 show the results of curve fitting based on the $\mathrm{Sn}$-incorporation model for (a) $\kappa^{3}$-weighted EXAFS functions and (b) radial structure functions of the sr-Ni plate at $-0.15 \mathrm{~V}$ and $0.05 \mathrm{~V}$, respectively. The EXAFS parameters obtained with curve fitting are

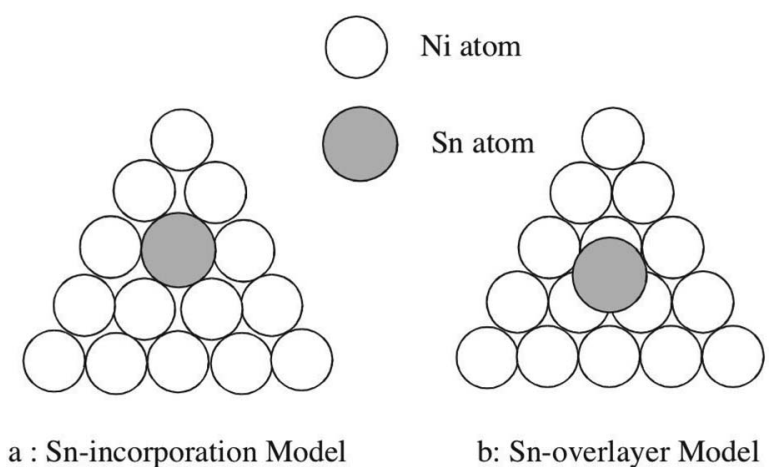

Figure 11. a: Sn-incorporation model and b: Sn-overlayer model proposed for geometrical configuration of $\mathrm{Sn}$ and $\mathrm{Ni}$ atoms corresponding to the $\mathrm{Sn}-\mathrm{Ni}$ shell. 

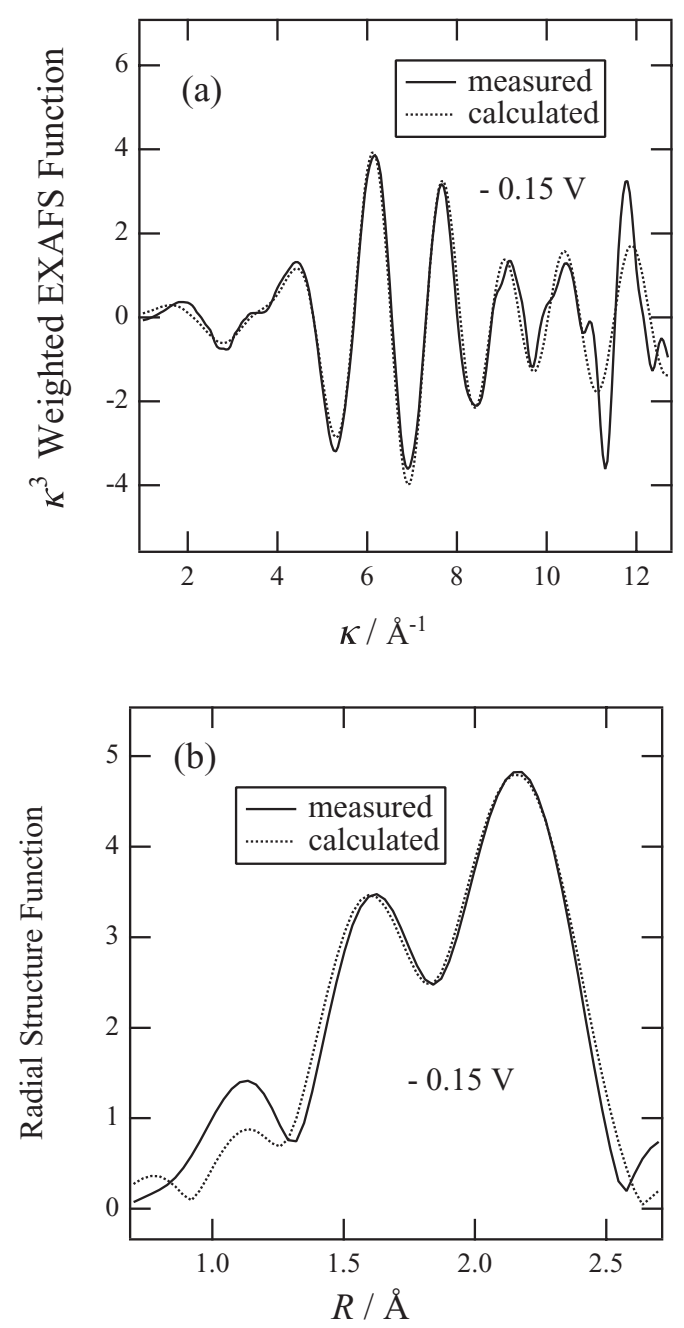

Figure 12. Results of curve fitting based on the Sn-incorporation model for (a) $\kappa^{3}$-weighted EXAFS function and (b) radial structure function of the $\mathrm{sr}-\mathrm{Ni}$ plate at $-0.15 \mathrm{~V}$.

listed in Table I. The inter-atomic distances between $\mathrm{Sn}$ and $\mathrm{O}$, $d_{\mathrm{Sn}-\mathrm{O}}=2.03 \sim 2.04 \AA$, and between $\mathrm{Sn}$ and $\mathrm{Ni}, d_{\mathrm{Sn}-\mathrm{Ni},}=2.55$ $\sim 2.57 \AA$ are almost independent of potential, while the coordination numbers of $\mathrm{Sn}-\mathrm{O}, N_{\mathrm{Sn}-\mathrm{O}}$, and of $\mathrm{Sn}-\mathrm{Ni}, N_{\mathrm{Sn}-\mathrm{Ni}}$, exhibit the opposite potential dependences, that is, $N_{\mathrm{Sn}-\mathrm{O}}$ increases from 1.5 to 2.9 but $N_{\text {Sn-Ni }}$ decreases from 7.1 to 4.6 as the potential shifts to the noble direction. The values of $d_{\mathrm{Sn}-\mathrm{O}}$ and $N_{\mathrm{Sn}-\mathrm{Ni}}$ for the sr-Ni plate at $-0.22 \mathrm{~V}$ could not be evaluated because of lacking in clear peak corresponding to the Sn-O interaction. The small values of $R_{\mathrm{f}}=0.004 \sim 0.012$ in
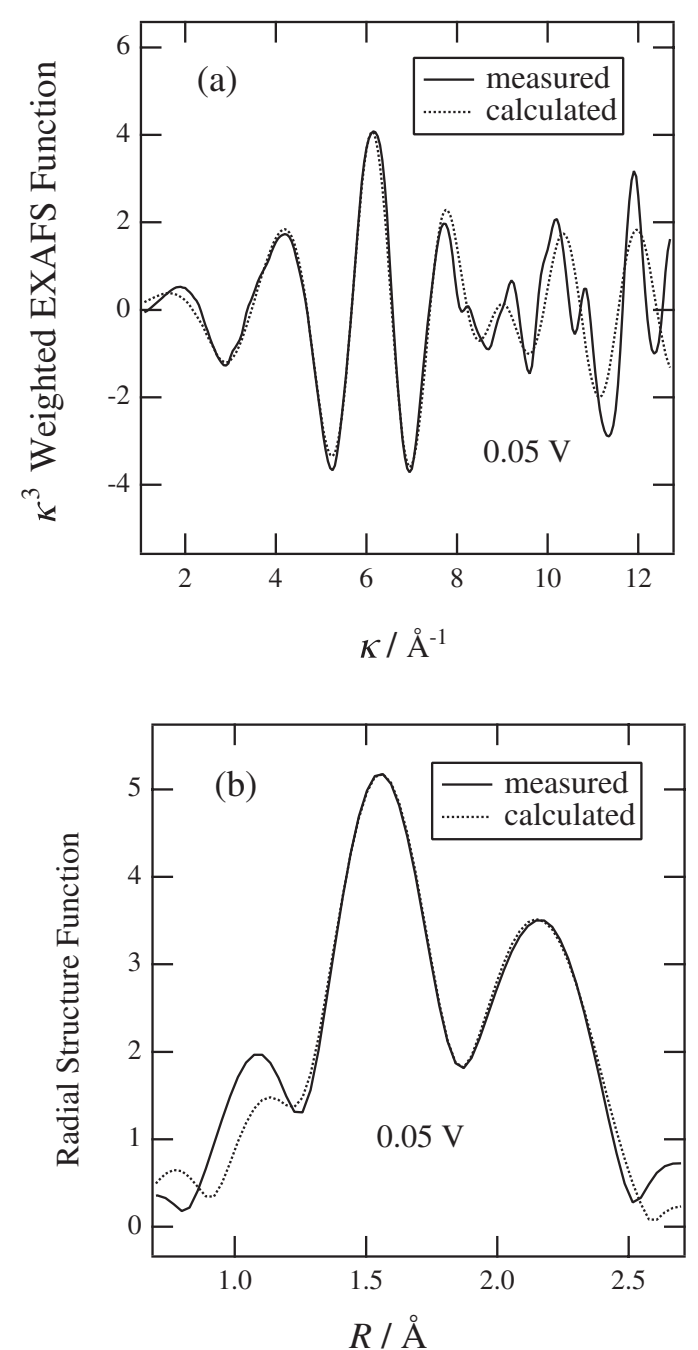

Figure 13. Results of curve fitting based on the Sn-incorporation model for (a) $\kappa^{3}$-weighted EXAFS function and (b) radial structure function of the sr-Ni plate at $0.05 \mathrm{~V}$.

Table I evidence the excellent match between measured and calculated curves.

The sr-Ni plate usually consists of polycrystalline surfaces which contain (111), (100) and (110) facets and defective sites, although the surface structure model suitable for Sn UPD layer on Ni is limited to the Ni (111) plane. For the Sn-incorporation model, the theoretical coordination numbers of $\mathrm{Ni}$ are 9,8 and 7 for the (111), (100) and (110) planes, respectively, which match the experimental values of $N_{\text {Sn-Ni }}$ in Table I. The limitation to the Ni (111) plane, therefore, may

Table I. EXAFS parameters obtained with curve fitting for two shells of Sn-O and Sn-Ni based on the Sn-incorporation model.

\begin{tabular}{|c|c|c|c|c|c|c|c|c|c|}
\hline \multicolumn{5}{|c|}{ Sn-O shell } & \multicolumn{5}{|c|}{ Sn-Ni shell } \\
\hline$E(\mathrm{~V})$ & $N_{\text {Sn-O }}$ & $d_{\mathrm{Sn-O}}(\AA)$ & $\sigma^{2}\left(\AA^{2}\right)$ & $\Delta E_{\mathrm{o}}(\mathrm{eV})$ & $N_{\text {Sn-Ni }}$ & $d_{\mathrm{Sn}-\mathrm{Ni}}(\AA)$ & $\sigma^{2}\left(\AA^{2}\right)$ & $\Delta E_{\mathrm{o}}(\mathrm{eV})$ & $R_{\mathrm{f}}$ \\
\hline-0.22 & - & - & - & - & 7.1 & 2.55 & 0.0109 & -2.57 & 0.012 \\
\hline-0.15 & 1.5 & 2.04 & 0.0012 & 3.07 & 5.7 & 2.57 & 0.0102 & 0.10 & 0.004 \\
\hline-0.05 & 1.9 & 2.03 & 0.0017 & 1.46 & 5.6 & 2.57 & 0.0108 & -0.59 & 0.008 \\
\hline 0.0 & 2.3 & 2.04 & 0.0026 & 4.58 & 4.8 & 2.57 & 0.0109 & -0.99 & 0.009 \\
\hline 0.05 & 2.9 & 2.03 & 0.0021 & 3.30 & 4.6 & 2.55 & 0.0109 & -3.14 & 0.005 \\
\hline
\end{tabular}

$E$, potential referred to the standard hydrogen electrode (SHE); $N_{\mathrm{Sn}-\mathrm{O}}$ and $N_{\mathrm{Sn}-\mathrm{Ni}}$, coordination numbers; $d_{\mathrm{Sn}-\mathrm{O}}$ and $d_{\mathrm{Sn}-\mathrm{Ni}}$, inter-atomic distances; $\sigma^{2}$, Debye-Waller factor; $\Delta E_{\mathrm{O}}$, energy shift; $R_{\mathrm{f}}$, R-factor (goodness-of-fit). Both uncertainties of $d_{\mathrm{Sn}-\mathrm{O}}$ and $d_{\mathrm{Sn}-\mathrm{Ni}}$ are $\pm 0.01 \AA \AA$. 
be unnecessary for the Sn-incorporation model. In general, the interatomic distance between metal and oxygen, $d_{\mathrm{M}-\mathrm{O}}$, for metal oxides increases with decreasing metal valence (e.g., $d_{\text {Sn-O }}=2.05 \AA$ for $\mathrm{SnO}_{2}{ }^{37}$ and $d_{\mathrm{Sn}-\mathrm{O}}=2.21 \AA$ for $\left.\mathrm{SnO}\right){ }^{37}$ The value of $d_{\text {Sn-O }}$ for the sr-Ni plate, however, is slightly small as compared with that $\left(d_{\mathrm{Sn}-\mathrm{O}}\right.$ $=2.05 \AA$ ) for $\mathrm{SnO}_{2}$ in spite of that $\mathrm{Sn}$ atoms are bonded with $\mathrm{Ni}$ atoms. This may result from the peculiar configuration of $\mathrm{Sn}$ atoms surrounded by $\mathrm{Ni}$ and $\mathrm{O}$ atoms as discussed later. As shown in Table I, the potential dependence of $N_{\mathrm{Sn}-\mathrm{Ni}}$ is compensated with that of $N_{\mathrm{Sn}-\mathrm{O}}$, i.e., the summation of $N_{\mathrm{Sn}-\mathrm{O}}+N_{\mathrm{Sn}-\mathrm{Ni}}=7.1 \sim 7.5$ is irrespective of potential. The Sn-incorporation model takes a theoretical value of $N_{\mathrm{Sn}-\mathrm{Ni}}=9$ for the $\mathrm{Ni}(111)$ plane if the $\mathrm{Ni}$ atoms in the first and second Ni layers for the sr-Ni plate occupy completely the fcc sites. The real surface of the sr-Ni plate would have the defective structure with partly vacant $\mathrm{Ni}$-fcc sites because of large surface roughness. It is deduced that the increase in Ni-vacant site leads to the decrease in $N_{\mathrm{Sn}-\mathrm{Ni}}$. The potential dependence of $N_{\mathrm{Sn}-\mathrm{Ni}}$ in Table I means that the $\mathrm{Ni}$ atoms surrounding central $\mathrm{Sn}$ atom are gradually removed from the fcc sites to create the Ni-vacant sites as the potential shifts to the noble direction. Moreover, the potential dependence of $N_{\text {Sn-O }}$ in Table I suggests that the number of oxygen atom bonded with central $\mathrm{Sn}$ atom increases to occupy the $\mathrm{Ni}$-vacant sites, which would stabilize energetically the Sn-UPD structure. In the XAFS study ${ }^{42}$ of nano-crystalline Pt electrode, it has been reported that $N_{\mathrm{Pt}-\mathrm{Pt}}$ decreases while $N_{\mathrm{Pt}-\mathrm{O}}$ increases as the potential shifts to the noble direction. The results are explained in terms of place exchange of $\mathrm{Pt}$ atom by $\mathrm{O}$ atom in fcc sites prior to the formation of $\mathrm{PtO}$ monolayer, which supports our explanation for the opposite potential dependences of $N_{\mathrm{Sn}-\mathrm{Ni}}$ and $\mathrm{N}_{\text {Sn-O }}$.

The value of $d_{\mathrm{Sn}-\mathrm{Ni}}=2.55 \sim 2.57 \AA$ in Table I is significantly small as compared with that $\left(d_{\mathrm{Sn}-\mathrm{Ni}}=2.65 \AA\right)$ expected for a hard sphere model based on the metallic radii $\left(r_{\mathrm{Sn}}=1.40 \AA\right.$ and $\left.r_{\mathrm{Ni}}=1.25 \AA\right)$ of bulk crystalline $\alpha-\mathrm{Sn}$ and $\mathrm{Ni}$. If the effective radius of $\mathrm{Ni}$ atoms surrounding central $\mathrm{Sn}$ atom is unchanged from that of the bulk, the effective radius of central $\mathrm{Sn}$ atom is estimated to be $r_{\mathrm{Sn}}=1.31 \AA$, which is less by $0.09 \AA$ than that $\left(r_{\mathrm{Sn}}=1.40 \AA\right)$ of bulk crystalline $\alpha$-Sn, indicating that the bond between $\mathrm{Sn}$ and $\mathrm{Ni}$ is covalent. ${ }^{43}$ The significant decreases in effective radius of the adsorbate at formation of surface alloy were reported for the vapor-deposition of Sn monolayer on $\mathrm{Ni}(111)^{44,45}$ or on $\mathrm{Cu}(111)^{46}$ and of $\mathrm{Pb}$ monolayer on $\mathrm{Ni}(111){ }^{47}$ These results are consistent with the value of $d_{\mathrm{Sn}-\mathrm{Ni},}=2.55 \sim 2.57$ $\AA$ for the sr-Ni plate obtained by fitting with the Sn-incorporation model. When Sn atoms are adsorbed on the Ni surface, the large compressive surface stress or surface strain would be produced due to the large difference between radii of $\mathrm{Sn}$ and $\mathrm{Ni}$ atoms as pointed out by Ibach. ${ }^{48}$ The decrease in $r_{\mathrm{Sn}}$ at the surface alloy formation in spite of the immiscibility of $\mathrm{Sn}$ in bulk $\mathrm{Ni}$ is energetically preferable since the relaxation of compressive surface stress or surface strain is brought by the decrease in $r_{\mathrm{Sn}}$. The decrease in $r_{\mathrm{Sn}}$ would influence the value of $d_{\mathrm{Sn}-\mathrm{O}}$ for the sr-Ni plate. The effective radius of $\mathrm{O}$ atom, $r_{\mathrm{O}}=0.67 \AA$ is estimated from the single-covalent bonding length ${ }^{49}$ between $\mathrm{O}-\mathrm{O}, d_{\mathrm{O}-\mathrm{O}}=1.34 \AA$. If assuming $d_{\mathrm{Sn}-\mathrm{O}}=r_{\mathrm{Sn}}+r_{\mathrm{O}}$, the value of $d_{\text {Sn-O }}=1.98 \AA$ is obtained by using the value of $r_{\mathrm{Sn}}=1.31 \AA$, indicating that the decrease in $r_{\mathrm{Sn}}$ brings the small value of $d_{\mathrm{Sn}-\mathrm{O}}$ for the sr-Ni plate as compared with that $\left(d_{\mathrm{Sn}-\mathrm{O}}=2.05 \AA\right)$ for $\mathrm{SnO}_{2}$.

It is known that $\mathrm{Ag}$ species adsorbed on $\mathrm{Au}^{50}$ and $\mathrm{Pb}$ species adsorbed on $\mathrm{Pt}^{51}$ in the UPD potential region are in metallic state. Our previous in situ XAS study has also revealed that the $\mathrm{Pb}$ species adsorbed on $\mathrm{Ni}$ in the UPD potential region are metallic. ${ }^{17}$ In contrast, it has been reported that the $\mathrm{Sn}$ species adsorbed on Pt in the UPD potential region are oxygenated. ${ }^{4}$ The Sn-UPD on Pt has been studied using a variety of electrochemical and spectroscopic techniques with relation to the electro-catalytic activity of Sn-decorated Pt. LamyPitara et al. ${ }^{3}$ have pointed out that the electrochemical and catalytic properties of Pt electrode are irreversibly modified by Sn-UPD and depend strongly on the Sn-UPD conditions. The irreversible modification by Sn-UPD was ascribed to the strong bonding of $\mathrm{Sn}$ atoms with $\mathrm{Pt}$ and $\mathrm{O}$ atoms. The XAS measurements ${ }^{4}$ at $\mathrm{Sn} \mathrm{K}$-edge made for the Sn-UPD on Pt, however, were unable to confirm the bond between $\mathrm{Sn}$ and Pt atoms. In the present XAS study for the Sn-UPD on $\mathrm{Ni}$, it has been confirmed that $\mathrm{Sn}$ atoms are bonded with $\mathrm{Ni}$ and $\mathrm{O}$ atoms.

Local structure of the Sn-UPD layer on Ni.- Ku and Overbury ${ }^{44}$ have found that when $\mathrm{Sn}$ monolayer evaporated on to the Ni (111) substrate is annealed at $650 \mathrm{~K}$ in vacuum, the $\mathrm{Sn}$ atoms are incorporated into the substrate surface to form a surface alloy phase with $(\sqrt{3} \times \sqrt{3}) R 30^{\circ}$ ordering (Sn surface coverage of one third monolayer). The surface alloy phase with $(\sqrt{3} \times \sqrt{3}) R 30^{\circ}$ is also formed by annealing the $\mathrm{Sn}$ monolayer evaporated on to the Pt (111) or $\mathrm{Cu}$ (111) substrate. ${ }^{45}$ Moreover, the formation of surface alloy with $(\sqrt{3} \times \sqrt{3}) R 30^{\circ}$ or $p(2 \times 2)$ was observed even at room temperature for the $\mathrm{Pb}$ monolayer evaporated on to the $\mathrm{Cu}(111) .{ }^{52}$ The nearest neighbor $\mathrm{Sn}-\mathrm{Ni}$ shell $\left(N_{\mathrm{Sn}-\mathrm{Ni}}=9\right)$ in the $\mathrm{Sn}$-incorporation model proposed for the Sn-UPD layer on $\mathrm{Ni}(111)$ has the same atomic configuration as that of the surface alloy phase with $(\sqrt{3} \times \sqrt{3}) R 30^{\circ}$ Assuming that the Sn-UPD layer on Ni takes the surface alloy structure with $(\sqrt{3} \times \sqrt{3}) R 30^{\circ}$ and the atomic radius of $\mathrm{Ni}$ atom $\left(r_{\mathrm{Ni}}=1.25 \AA\right)$ is unchanged, the values of $d_{\mathrm{Sn}-\mathrm{Sn}}=4.33 \AA$ and $N_{\mathrm{Sn}-\mathrm{Sn}}=6$ are expected as the EXAFS parameters corresponding to the nearest neighbor $\mathrm{Sn}$ Sn shell. The evaluation of $d_{\mathrm{Sn}-\mathrm{Sn}}$ and $N_{\mathrm{Sn}-\mathrm{Sn}}$ from the radial structure functions in Fig. 8, however, could not be achieved because of the noisy EXAFS data in the range of $\kappa>13 \AA^{-1}$ (in Fig. 7) that would lead to no systematic potential dependences of the radial structure functions in the range of $R>2.5 \AA$. Besides, some of the small broad peaks or multiple peaks in the range of $R>2.5 \AA$ of Fig. 8 may be associated with the second near neighbor Sn-O or Sn-Ni shell, which makes more difficult the separation between the nearest neighbor $\mathrm{Sn}-\mathrm{Sn}$ shell and the second near neighbor $\mathrm{Sn}-\mathrm{O}$ or $\mathrm{Sn}-\mathrm{Ni}$ shell. At present, therefore, it is unable to ensure the formation of surface alloy phase with $(\sqrt{3} \times \sqrt{3}) R 30^{\circ}$ from the radial structure functions of Fig. 8.

The real surface structure of the Sn-UPD layer on Ni would be much complicated than the simplified Sn-incorporation model. The sr-Ni plate surface may have many stepped and defective structures because of the large surface roughness. The coordination numbers $\left(N_{\mathrm{Sn}-\mathrm{O}}\right.$ and $\mathrm{N}_{\mathrm{Sn}-\mathrm{Ni}}$ ) would not be uniform for each $\mathrm{Sn}$-occupation site. The values of $N_{\mathrm{Sn}-\mathrm{O}}$ and $\mathrm{N}_{\mathrm{Sn}-\mathrm{Ni}}$ obtained in Table I are only averaged ones for each Sn-occupation site. Nevertheless, the EXAFS analysis based on the simplified Sn-incorporation model could throw a new light into the Sn-UPD layer on Ni which has never been studied so far. Particularly, it is remarkable that the $\mathrm{Sn}$ atoms are bonded with $\mathrm{O}$ atoms in addition to the covalent bonding with $\mathrm{Ni}$ atoms as surface alloy. Moreover, as the potential shift to the noble direction, $N_{\mathrm{Sn}-\mathrm{O}}$ increases while $\mathrm{N}_{\mathrm{Sn}-\mathrm{Ni}}$ decreases in spite of that both $d_{\mathrm{Sn}-\mathrm{O}}$ and $d_{\mathrm{Sn}-\mathrm{Ni}}$ are potential-independent. It is sure that the strong inhibition effect of $\mathrm{Sn}$ on aqueous corrosion of $\mathrm{Ni}$ (Fig. 1) results from the bonding of $\mathrm{Sn}$ atoms with $\mathrm{O}$ atoms in addtion to the covalent bonding of Sn atoms with $\mathrm{Ni}$ atoms. In the case of the inhibition effect of $\mathrm{Pb}$ on aqueous corrosion of $\mathrm{Ni}$, although the anodic dissolution of $\mathrm{Ni}$ is suppressed by the UPD of metallic $\mathrm{Pb}$ on $\mathrm{Ni}$, the re-activation of anodic dissolution takes place due to the anodic stripping of metallic $\mathrm{Pb}$ as the potential shifts to the noble direction prior to the passivation. ${ }^{16}$ In the case of the inhibition effect of $\mathrm{Sn}$ on aqueous corrosion of $\mathrm{Ni}$, the $\mathrm{Sn}$-UPD layer on $\mathrm{Ni}$ suppresses not only the anodic dissolution of $\mathrm{Ni}$ but also the re-activation of anodic dissolution as shown in Fig. 1. The bonding of $\mathrm{Sn}$ atoms with $\mathrm{O}$ atoms and the increase in $N_{\mathrm{Sn}-\mathrm{O}}$ with shift in potential to the noble direction suppress the anodic stripping of the Sn-UPD layer on $\mathrm{Ni}$ since the oxygenated $\mathrm{Sn}$ species could remain on the $\mathrm{Ni}$ surface to cover the active dissolution sites. Our recent XPS analysis ${ }^{15}$ has confirmed that the oxygenated $\mathrm{Sn}$ species are present on $\mathrm{Ni}$ in the passive potential region. In situ XAS measurements have succeeded in proving the local structure of the Sn-UPD layer on Ni and have contributed to understanding on an atomic level of the Sn inhibition effect on aqueous corrosion of $\mathrm{Ni}$. 


\section{Conclusions}

In situ XAS measurements at Sn K-edge are made by using the periodical emersion method and employing the sr-Ni plate to probe the local structure of Sn-UPD layer on $\mathrm{Ni}$ in $0.2 \mathrm{M}$ perchloric acid and to provide a new insight into the inhibition effect of $\mathrm{Sn}$ on aqueous corrosion of $\mathrm{Ni}$. The EXAFS analysis indicates that the $\mathrm{Sn}$ atoms are substituted at fcc sites in the first Ni layer and further bonded with oxygen atoms. Both the values of $d_{\text {Sn-O }}=2.03 \sim 2.04 \AA$ and $d_{\mathrm{Sn}-\mathrm{Ni}}=2.55$ $\sim 2.57 \AA$ are independent of potential. The value of $r_{\mathrm{Sn}}=1.31 \AA$ obtained from $d_{\mathrm{Sn}-\mathrm{Ni}}=2.55 \sim 2.57 \AA$ assuming $r_{\mathrm{Ni}}=1.25 \AA$ for the substrate Ni is significantly less than that $\left(r_{\mathrm{Sn}}=1.40 \AA\right)$ for bulk $\alpha-\mathrm{Sn}$, indicating that the bond between $\mathrm{Sn}$ and $\mathrm{Ni}$ atoms is covalent. The slightly small value of $d_{\text {Sn-O }}=2.03 \sim 2.04 \AA$ as compared with that $\left(d_{\mathrm{Sn}-\mathrm{O}}=2.05\right) \AA$ for $\mathrm{SnO}_{2}$ results from the decrease in $r_{\mathrm{Sn}}$ due to the strong covalent bond between $\mathrm{Sn}$ and $\mathrm{Ni}$ atoms like a surface alloy. As the potential shifts to the noble direction, the value of $N_{\text {Sn-O }}$ increases from 1.5 to 2.9 while the value of $N_{\mathrm{Sn}-\mathrm{Ni}}$ decreases from 7.1 to 4.6. The value of $N_{\mathrm{Sn}-\mathrm{O}}+N_{\mathrm{Sn}-\mathrm{Ni}}=7.1 \sim 7.5$, however, is irrespective of potential.

The bonding of Sn atoms with $\mathrm{O}$ atoms in addition to the covalent bond between $\mathrm{Sn}$ and $\mathrm{Ni}$ atoms prevents the anodic stripping of $\mathrm{Sn}$ UPD layer and the strong inhibition effect of $\mathrm{Sn}$ on aqueous corrosion of $\mathrm{Ni}$ is brought by the coverage of the active dissolution sites with oxygenated Sn species. The difference between inhibition effects of $\mathrm{Sn}$ and $\mathrm{Pb}$ on aqueous corrosion of $\mathrm{Ni}$ is directly associated with the difference in local structure between $\mathrm{Sn}$-and $\mathrm{Pb}$-UPD layers on Ni. In-situ XAS measurements have revealed the difference in local structure between $\mathrm{Sn}$ - and $\mathrm{Pb}$-UPD layers on Ni from which the difference between corrosion-inhibition mechanism of $\mathrm{Sn}$ and $\mathrm{Pb}$ for $\mathrm{Ni}$ is resolved on an atomic level.

\section{References}

1. S. Szabo, J. Electroanal. Chem., 172, 359 (1984).

2. R. Holze and B. Bittins-Cattaneo, Electrochim. Acta, 33, 353 (1988).

3. E. Lamy-Pitara, L. EI Quazzani-Benhima, J. Barbier, M. Cahoreau, and J. Caisso, J. Electroanal. Chem., 372, 233 (1994).

4. S. Mukerjee and J. McBreen, J. Electrochem. Soc., 146, 600 (1999).

5. S. Motoo, M. Shibata, and M. Watanabe, J. Electroanal. Chem., 110, 103 (1998).

6. S. Motoo and M. Watanabe, J. Electroanal. Chem., 69, 429 (1976).

7. Yu. B. Vassiliev, V. S. Bagotzky, N. V. Osetrova, and A. A. Mikkailova, J. Electroanal. Chem., 97, 63 (1979).

8. J. Sobkowski, K. Franaszczuk, and A. Piasecki, J. Electroanal. Chem., 196, 145 (1985).

9. A. N. Haner and P. N. Ross, J. Phys. Chem., 95, 3740 (1991).

10. Z. D. Wei, L. L. Li, Y. H. Luo, C. Yan, C. X. Sun, G. Z. Yin, and P. K. Shen, J. Phys. Chem. B, 110, 26055 (2006).

11. W. R. Buck, III and H. Leidheiser Jr., J. Electrochem. Soc., 104, 474 (1957).

12. J. A. Schrophire, J. Electrochem. Soc., 107, 740 (1960)

13. M. S. Morad, J. Appl. Electrochem., 37, 661 (2007).

14. N. D. Nam, M. J. Kim, Y. W. Jang, and J. G. Kim, Corros. Sci., 52, 14 (2010).
15. M Seo, H. Habazaki, and T Nakayama, to be submitted

16. M. Seo, K. Fushimi, H. Habazaki, and T. Nakayama, Corros. Sci., 50, 3139 (2008).

17. M. Seo, K. Fushimi, Y. Aoki, H. Habazaki, M. Inaba, M. Yokomizo, T. Hayakawa, and T. Nakayama, J. Electroanal. Chem., 671, 7 (2012).

18. H. D. Abruna, in Electrochemical Interfaces: Modern Techniques for In-situ Interface Charctrerization, H. D. Abruna, Editor, Capt. 1, VCH Pub. Inc., New York (1991).

19. D. Lützenkirchen-Hecht and H.-H. Strehblow, in Analytical Methods in Corrosion Science and Engineering, P. Marcus and F. Mansfeld, Editors, Chapt. 6, CRC Press, Florida (2006)

20. M. G. Samant, G. L. Borges, J. G. Gordon II, O. R. Melroy, and L. Blum, J. Am. Chem. Soc., 109, 5970 (1987).

21. O. R. Melroy, M. G. Samant, G. L. Borges, J. G. Gordon II, L. Blum, J. H. White, M. J. Albarelli, M. MicMillan, and H. D. Abruna, Langmuir, 4, 728 (1988).

22. A. Tadjeddine, G. Tourillon, and G. Guay, Electrochim. Acta, 36, 1859 (1991).

23. A. Tadjeddine, A. Lahrichi, and G. Tourillon, J. Electroanal. Chem., 360, 261 (1993).

24. Y. Soldo, E. Sibert, G. Tourillon, J. L. Hazemann, J. P. Lévy, D. Aberdam, R. Faure, and R. Durand, Electrochim. Acta, 47, 3081 (2002).

25. R. Durand, R. Faure, D. Aberdam, C. Salem, G. Tourillon, D. Guay, and M. Ladouceur, Electtochim. Acta, 37, 1977 (1992).

26. J. R. I. Lee, R. L. O’Malley, T. J. O’Connell, A. Vollmer, and T. Rayment, Electrochim. Acta, 55, 8532 (2010).

27. W. N. Hansen, C. L. Wang, and T. W. Humpherys, J. Electroanal. Chem., 93, 87 (1978).

28. D. M. Kolb and W. N. Hansen, Surf. Sci., 79, 205 (1979).

29. I. C. Stefan and D. A. Scherson, J. Electroanal. Chem., 554-555, 361 (2003).

30. M. Pourbaix, in Atlas of Electrochemical Equilibria in Aqueous Solutions, Pergamon Press, Oxford (1966).

31. D. M. Kolb, M. Przasnyski, and H. Gerischer, J. Electroanal. Chem., 54, 25 (1974).

32. D. M. Kolb, in Advances in Electrochemistry and Electrochemical Engineering, Vol. 11, H. Gerischer and C. W. Tobias, Editors, John Wiley \& Sons, New York (1978).

33. A. Koma, K. Yagi, M. Tsukada, and M. Aono, Handbook of Surface Physics Technology, Maruzen Co., Tokyo (1987).

34. B. MacDougall and M. Cohen, J. Electrochem. Soc., 123, 191 (1976)

35. E. Herrero, L. J. Buller, and H. D. Abruna, Chem. Rev., 101, 1897 (2001).

36. D. Grandjean, R. E. Benfield, C. Nayral, A. Maisonnat, and B. Chaudret, J. Phys. Chem. B, 108, 8876 (2004).

37. A. F. Wells in Structural Inorganic Chemistry, 3rd. Ed., Oxford University Press, London (1962).

38. M. L. Varsanyi, J. Jaen, A. Vertes, and L. Kiss, Electrochim. Acta, 30, 529 (1985).

39. R. Diaz, S. Joiret, A. Cuesta, I. Diez-Perez, P. Allongue, C. Gutierrez, P. Gorostza, and F. Sanz, J. Phys. Chem. B, 108, 8173 (2004).

40. A. L. Ankudinov, B. Ravel, J. J. Rehr, and S. D. Condrason, Phys. Rev. B, 58, 7565 (1998).

41. A. L. Ankudinov, C. E. Bouldin, J. J. Rehr, J. Sim, and H. Hung, Phys. Rev. B, 61, 104107 (2002).

42. M. Teliska, W. E. O'Grady, and D. E. Ramaker, J. Phys. Chem. B, 109, 8076 (2005).

43. D. P. Woodruff and J. Robinson, Appl. Surf. Sci., 219, 1 (2003).

44. Y. Ku and S. H. Overbury, Surf. Sci., 273, 341 (1992).

45. D. P. Woodruff and E. Vlieg, in The Chemical Physics of Solid Surfaces, D. P. Woodruff, Editor, Vol. 10, Chapt. 8, Elsevier Science, Amsterdam (2002).

46. S. H. Overbury and Y. Ku, Phys. Rev. B, 46, 7868 (1992).

47. D. Brown, P. D. Quinn, D. P. Woodruff, P. Bailey, and C. Q. Noakes, Phys. Rev. B, 61, 7706 (2000)

48. H. Ibach, Surf. Sci. Rep., 29, 193 (1997).

49. L. Pauling, in The Nature of the Chemical Bond and the Structure of Molecules and Crystals, 3 rd. Ed., Cornell University Press, New York (1960) p. 351.

50. M. G. Samant, G. Borges, and D. R. Melroy, J. Electrochem. Soc., 140, 421 (1993).

51. J. McBreen and M. Sansone, J. Electroanal. Chem., 373, 227 (1994).

52. C. Nadgl, O. Hallen, E. Platzgummer, M. Schmid, and P. Varga, Surf. Sci., 321, 237 (1994). 